Henderson, M. E. K. (1956). J. gen. Microbiol. 14, 684-691

\title{
A Study of the Metabolism of Phenolic Compounds by Soil Fungi Using Spore Suspensions
}

\author{
By MOIRA E. K. HENDERSON \\ The Macaulay Institute for Soil Research, Craigiebuckler, Aberdeen
}

SUMMARY : Spore suspensions were used to investigate the metabolism of $p$-hydroxybenzaldehyde, ferulic acid, syringaldehyde and vanillin by Haplographium sp., Hormodendrum sp., Penicillium sp. and Spicaria sp. The intermediate products of their metabolism, $p$-hydroxybenzoic, syringic and vanillic acids, were found to be attacked by adaptive enzymes. The formation of these enzymes was greatly decreased by the antibiotic citrinin.

The results of experiments, based on a technique in which fungal spore suspensions were used in place of hyphae, are presented in this paper. Under investigation was the metabolism of certain phenolic compounds related to lignin, which have already been reported to be utilized by soil microfungi as sources of carbon (Henderson \& Farmer, 1955).

\section{METHODS}

Organisms. The following fungi were used in this investigation: Haplographium sp. from deciduous woodland soil; Hormodendrum sp. no. 1 from sand under Scots Pine in an afforested sand dune; Penicillium sp. no. 13 from moorland soil; Spicaria sp. from foreshore sand. These fungi were all used in the previous investigation (Henderson \& Farmer, 1955).

Preparation of spore suspensions. The method used was that previously described (Henderson, 1955). Spores were obtained from cultures of the fungi grown on potato glucose agar for 7 days at $22^{\circ}$. The fungi were grown on strips of cellophan which were laid on the surface of the agar and which were inoculated by streaking with spores. The strips, bearing the growth, were transferred to tubes containing a solution of Tween $80(1 / 1000, v / v)$ in which the spores suspended uniformly. On shaking gently the spores became detached while the mycelium adhered to the cellophan. The spores were centrifuged, washed twice in distilled water and finally suspended in distilled water. All operations were carried out aseptically. The density of the suspensions was measured by means of a haemocytometer.

Solutions added to Warburg flasks. The flasks and all solutions, with the exception of $\mathrm{KOH}$, were sterilized by autoclaving or by filtration in the case of the phenolic compounds, and all operations were carried out aseptically. Solutions added to the main compartment were: $0.5 \mathrm{ml}$. mineral salts; $0.5 \mathrm{ml}$. Difco yeast extract; $0.5 \mathrm{ml}$. buffer and $1.0 \mathrm{ml}$. spore suspension. $0.5 \mathrm{ml}$. substrate was added to the side arrn and $0.2 \mathrm{ml} .5 \%(\mathrm{w} / \mathrm{v}) \mathbf{K O H}$ to the centre cup. The mineral salts solution was a modified Czapek mineral salts solution, as used in the growth experiments (Henderson \& Farmer, 1955). It contained: $\mathrm{NaNO}_{3}, 1.5$ g.; $\mathrm{MgSO}_{4} .7 \mathrm{H}_{2} \mathrm{O}, 0.25$ g.; $\mathrm{KH}_{2} \mathrm{PO}_{4}, 0.5$ g.; $\mathrm{KCl}, 0.25$ g. dissolved in $500 \mathrm{ml}$. water. The $\mathrm{pH}$ value and kind of buffer used for each organism was 
determined by preliminary experiments (see later). The spores were incubated overnight in the Warburg vessels before addition of substrates and the concentration of yeast extract present was such that it stimulated germination but did not support too high a basal rate of respiration on the following day. The concentration of yeast extract finally used for Haplographium sp., Penicillium sp. and Spicaria sp. was $0.125 \%(\mathrm{w} / \mathrm{v})$ and for Hormodendrum sp. $0 \cdot 48 \%(\mathrm{w} / \mathrm{v})$.

The experiments were conducted at $25^{\circ}$ in air. Following the overnight incubation, readings were taken at 30 or $60 \mathrm{~min}$. intervals for 1-2 hr. to establish the basal respiration rate. Substrates were then tipped in and oxygen uptake measurements were continued at 30 or $60 \mathrm{~min}$. intervals for the duration of the experiments, which was generally 7-8 hr.

\section{RESULTS}

\section{Influence of $\mathrm{pH}$ value on the respiration rates of the fungi}

Experiments, which were designed to find the optimum $\mathrm{pH}$ value for each fungus, revealed that the respiratory rates were highest at $\mathrm{pH}$ values which corresponded very closely with those of the various 'soils' from which the fungi were isolated. McIlvaine's citrate + phosphate buffer (Clark, 1928) was used at $\mathrm{pH} \mathrm{3,5}$ and 7 with each fungus. In these experiments no source of carbon was added in addition to that present in the yeast extract.

Penicillium sp., which showed a distinct optimum at $\mathrm{pH} 3$, was isolated from raw heather humus, the $\mathrm{pH}$ value of which was 3.5. Spicaria sp. respired more rapidly at $\mathrm{pH} 5$ and 7 than at $\mathrm{pH} 3$. This species was isolated from foreshore sand of $\mathrm{pH} \mathrm{7 \cdot 3.} \mathrm{Hormodendrum} \mathrm{sp.,} \mathrm{isolated} \mathrm{from} \mathrm{sand} \mathrm{under} \mathrm{Scots} \mathrm{Pine} \mathrm{of}$ pH 4.2, showed a distinct optimum at pH 5 with McIlvaine's buffer. However, as this species was found to oxidize citric acid, Sørensen's inorganic phosphate buffer (Clark, 1928) was used at $\mathrm{pH} \mathbf{5 \cdot 3}$, which is the lowest value of its range, for this fungus. Sørensen's buffer at $\mathrm{pH} 5 \cdot 3$ was also used for Haplographium sp. which was isolated from deciduous woodland soil of $\mathrm{pH} 5 \cdot 7$.

\section{Respiration in the presence of phenolic compounds}

In these experiments $0.5 \mathrm{ml}$. of $0.1 \%(\mathrm{w} / \mathrm{v})$ solutions of $p$-hydroxybenzaldehyde, syringaldehyde or vanillin or of $0.05 \%(\mathrm{w} / \mathrm{v})$ ferulic acid were tipped into the vessels from the side arms after the overnight incubation period. The results obtained from experiments with the four fungi (see Table 1) resembled closely those previously obtained from growth experiments (Henderson \& Farmer, 1955). The latter experiments indicated that $p$-hydroxybenzaldehyde was the most readily utilizable compound and none of the above species left any residue of it in the culture media. Similarly, all four gave rapid oxygen uptakes on the addition of $p$-hydroxybenzaldehyde to spore suspensions. None of these species left any vanillin unaltered in the growth experiments, and the addition of this substance to spore suspensions gave rise to increased oxygen uptakes. In growth experiments referred to above, Haplographium sp., Penicillium sp. and Spicaria sp. all left residues of syringaldehyde which in the 
case of the first two amounted to more than half of that added originally. Hormodendrum sp. removed it entirely by the end of the growth period, but it was more slowly attacked by this fungus than were the other three compounds. The slower rate of attack on this compound was confirmed by the respiration studies. Haplographium sp. Penicillium sp. and Spicaria sp. gave a small

Table 1. Respiration of Haplographium sp., Hormodendrum sp., Penicillium $s p$. and Spicaria sp. on p-hydroxybenzaldehyde, ferulic acid, syringaldehyde and vanillin

$1 \mathrm{ml}$. of spore suspension added to vessels (Haplographium $3.1 \times 10^{9} ;$ Hormodendrum $9 \cdot 3 \times 10^{8} ;$ Penicillium?; Spicaria $1.2 \times 10^{9}$ spores $/ \mathrm{ml}$.) $+0.5 \mathrm{ml}$. mineral salts $+0.5 \mathrm{ml}$. buffer (Haplographium and Hormodendrum Sørensen's phosphate buffer $\mathrm{pH} 5 \cdot 3 ;$ Penicillium MeIlvaine's citrate-phosphate buffer pH 3.0; Spicaria Mcllvaine's citrate-phosphate buffer $\mathrm{pH} 7.0)+0.5 \mathrm{ml}$. yeast extract (Haplographium, Penicillium and Spicaria $0.125 \%$; Hormodendrum $0.48 \%(\mathrm{w} / \mathrm{v}))$. Centre cup contained $0.2 \mathrm{ml} .5 \%(\mathrm{w} / \mathrm{v}) \mathrm{KOH}$. $0.5 \mathrm{ml}$. substrates tipped in from side arms - $p$-hydroxybenzaldehyde, syringaldehyde and vanillin $0.1 \%(w / v)$; ferulic acid $0.05 \%(w / v)$.

\begin{tabular}{|c|c|c|c|c|}
\hline \multirow[b]{2}{*}{ Substrate } & \multicolumn{4}{|c|}{$\begin{array}{c}\mu \mathrm{l} \text {. oxygen uptake over the } 5 \mathrm{hr} \text {. period following } \\
\text { the addition of substrates }\end{array}$} \\
\hline & $\begin{array}{l}\text { Haplo- } \\
\text { graphium }\end{array}$ & $\begin{array}{l}\text { Hormo- } \\
\text { dendrum }\end{array}$ & Penicillium & Spicaria \\
\hline None & $15 \cdot 8$ & $31 \cdot 3$ & $85 \cdot 8$ & $121 \cdot 9$ \\
\hline$p$-Hydroxybenzaldehyde & $291 \cdot 7$ & $547 \cdot 3$ & $364 \cdot 7$ & $197 \cdot 7$ \\
\hline Ferulic acid & $111 \cdot 1$ & $357 \cdot 2$ & $114 \cdot 4$ & $143 \cdot 1$ \\
\hline Syringaldehyde & $36 \cdot 4$ & $225 \cdot 3$ & $104 \cdot 7$ & $135 \cdot 2$ \\
\hline Vanillin & $332 \cdot 8$ & $719 \cdot 0$ & $108 \cdot 5$ & $156 \cdot 6$ \\
\hline
\end{tabular}

increase with it, while Hormodendrum sp. gave an increase which was much lower than was shown with the other phenolic compounds. All four species removed ferulic acid completely during the growth period and all four gave increased oxygen uptakes with this substance. Thus all the results obtained from the Warburg experiments were fully in accord with the previous observations made with these organisms.

Further experiments were carried out in which intermediate products of the metabolism of $p$-hydroxybenzaldehyde, ferulic acid, syringaldehyde and vanillin were added as substrates. Previously it was shown that ferulic acid and vanillin are converted to venillic acid and syringaldehyde to syringic acid (Henderson \& Farmer, 1955). Evidence has now been obtained (Henderson, unpublished) that $p$-hydroxybenzaldehyde is converted to $p$-hydroxybenzoic acid by Hormodendrum sp. and Penicillium sp. These acid intermediates were added to the Warburg flasks to give a final concentration of $0.0083 \mathrm{M}$ when mixed with the other contents. The most noticeable feature of the respiration rates (Table 2) was the slow rate at which syringic and vanillic acids were oxidized. Penicillium sp. and Spicaria sp. showed no increase over the endogenous rate on addition of these acids. Hormodendrum sp. showed a very small increase with syringic acid but vanillic acid was oxidized at a more rapid rate. while Haplographium gave a small increase with both acids. $p$-Hydroxybenzoic acid was oxidized at an increased rate by all four fungi. 
The rapid rate of oxygen uptake with $p$-hydroxybenzoic acid compared with the other two acids, may explain the failure to detect it as an intermediate in ordinary growth culture media. It is probable that it is further metabolized whenever it is formed and may therefore never accumulate in the media in any quantity. Neither Haplographium sp. nor Hormodendrum sp. left any trace of any of the acids in the media during the 21-day growth experiments, but

Table 2. Respiration of Haplographium sp., Hormodendrum sp., Penicillium $s p$. and Spicaria sp. on p-hydroxybenzoic, syringic and vanillic acids

$1 \mathrm{ml}$. of spore suspension added to vessels (Haplographium $7 \cdot 1 \times 10^{8} ;$ Hormodendrum $6 \cdot 1 \times 10^{8} ;$ Penicillium $1 \cdot 1 \times 10^{9} ;$ Spicaria ? spores $/ \mathrm{ml}$. $)+0.5 \mathrm{ml}$. mineral salts solution $+0.5 \mathrm{ml}$. buffer (Haplographium and Hormodendrum Sørensen's phosphate buffer pH 5-3; Penicillium McIlvaine's citrate-phosphate buffer pH 3.0; Spicaria McIlvaine's citrate-phosphate buffer $\mathrm{pH} \mathrm{7.0)}+\mathbf{0 . 5} \mathrm{ml}$. yeast extract (Haplographium, Penicillium and Spicaria $0 \cdot 125 \%$; Hormodendrum $0.48 \%(\mathrm{w} / \mathrm{v})$ ). Centre cup contained $0.2 \mathrm{ml} .5 \%(\mathrm{w} / \mathrm{v}) \mathrm{KOH} .0 .5 \mathrm{ml}$. substrate $(0 \cdot 05 \mathrm{M})$ tipped in from side-arms.

$\mu \mathrm{l}$. oxygen uptake over the $\mathbf{5} \mathrm{hr}$. period following the addition of substrates

\begin{tabular}{lcccc}
\multicolumn{1}{c}{ Substrate } & $\begin{array}{c}\text { Haplo- } \\
\text { graphium }\end{array}$ & $\begin{array}{c}\text { Hormo- } \\
\text { dendrum }\end{array}$ & Penicillium & Spicaria \\
None & $\mathbf{2 2 \cdot 1}$ & $\mathbf{2 9 \cdot 5}$ & $\mathbf{1 7 6} \cdot \mathbf{1}$ & $\mathbf{2 0 4 \cdot 5}$ \\
p-Hydroxybenzoic acid & $\mathbf{2 7 3 \cdot 7}$ & $\mathbf{6 8 \cdot 7}$ & $\mathbf{3 5 1} \cdot \mathbf{9}$ & $\mathbf{2 7 3 \cdot 7}$ \\
Syringic acid & $\mathbf{4 9 \cdot 5}$ & $\mathbf{3 9 \cdot 4}$ & $\mathbf{1 6 7 \cdot 7}$ & $\mathbf{2 0 5 \cdot 8}$ \\
Vanillic acid & $\mathbf{3 7 \cdot 4}$ & $\mathbf{7 0 \cdot 7}$ & $\mathbf{1 6 8 \cdot 5}$ & $\mathbf{1 9 0 \cdot 4}$
\end{tabular}

Penicillium sp. and Spicaria sp. left some syringic acid and vanillic acid. The results from the respiration experiments with these species indicate that the acids are more slowly attacked than the corresponding aldehydes, which may explain the accumulation of the acids in the culture media as found with several fungi (Henderson \& Farmer, 1955).

\section{Use of spore suspensions for adaptation studies}

The curves for rate of oxygen uptake for some of the fungi in the presence of the acid intermediates suggested that they were being oxidized by adaptive enzymes. Therefore the technique for studying the metabolism of fungal spores in the Warburg apparatus was modified according to the exposure technique of Silliker \& Rittenberg (1951) to enable investigations into the possible occurrence of adaptation to be made (see Stanier, 1947). For this purpose the spores were incubated overnight in the presence of the substrates, during which time the latter were completely or almost completely utilized. In order to test for any residual respiration a control flask was kept to which only water was added. The presumed adaptive response was shown most clearly in the absence of yeast extract, which was therefore omitted in this part of the work. In the morning the taps were closed and readings were taken at $30 \mathrm{~min}$. intervals for a period of 1.5-2 hr., whereupon the suspected intermediates were tipped in from the side arms. Haplographium sp., Hormodendrum sp. and Penicillium sp. were used for these studies. 
Hormodendrum sp. spore suspensions preincubated with $p$-hydroxybenzaldehyde, ferulic acid, vanillin or syringaldehyde gave positive adaptive responses with the corresponding acids known to be intermediates in their

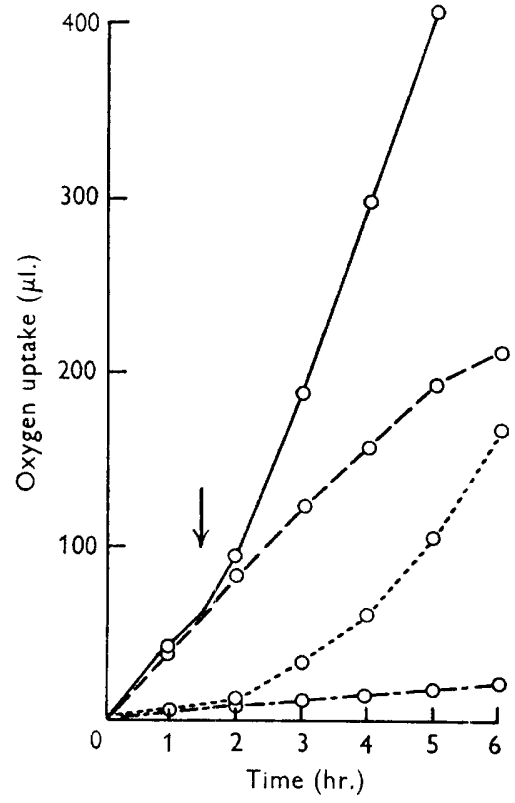

Fig. 1

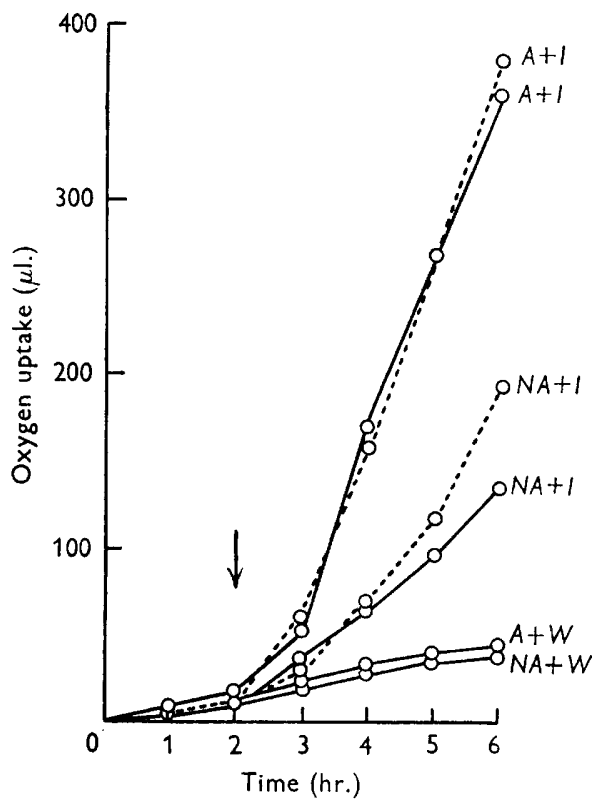

Fig. 2

Fig. 1. Hormodendrum sp. Adaptation studies. $p$-Hydroxybenzaldehyde : $p$-hydroxybenzoic acid. Each vessel contained: $1 \mathrm{ml}$. spore suspension $\left(5.5 \times 10^{8}\right.$ spores per ml.) $+0.5 \mathrm{ml}$. Sørensen's phosphate buffer pH $5 \cdot 3+0.5 \mathrm{ml}$. mineral salts solution $+0.5 \mathrm{ml}$. $p$-hydroxybenzaldehyde $(0.1 \%$, w/v) or $0.5 \mathrm{ml}$. water. Centre cup contained $0.2 \mathrm{ml} .5 \%(\mathrm{w} / \mathrm{v}) \mathrm{KOH}, 0.5 \mathrm{ml}$. $p$-hydroxybenzoic acid $(0.05 \mathrm{~m})$ or $0.5 \mathrm{ml}$. water tipped in from side-arm. - Spores adapted by overnight incubation with $p$-hydroxybenzaldehyde; -..... spores incubated overnight without $p$-hydroxybenzaldehyde. $p$-Hydroxybenzoic acid added to these two where indicated by arrow. --- , spores incubated overnight with $p$-hydroxybenzaldehyde, water added where indicated by arrow ; - - - - , spores incubated overnight without $p$-hydroxybenzaldehyde, water added where indicated by arrow.

Fig. 2. Hormodendrum sp. Inhibition by citrinin of adaptation to $p$-hydroxybenzoic acid. Spore suspension contained $4.0 \times 10^{8}$ spores per ml. Each vessel contained: $1 \mathrm{ml}$. spore suspension $+0.5 \mathrm{ml}$. Sørensen's phosphate buffer pH $5 \cdot 3+0.5 \mathrm{ml}$. mineral salts solution $+0.5 \mathrm{ml}$. $p$-hydroxybenzaldehyde $(0.1 \%, \mathrm{w} / \mathrm{v})$ or $0.5 \mathrm{ml}$. water. Centre cup contained $0.2 \mathrm{ml} .5 \%(\mathrm{w} / \mathrm{v}) \mathrm{KOH}$. $0.5 \mathrm{ml}$. citrinin $(500 \mu \mathrm{g} . / \mathrm{ml}$.) or $0.5 \mathrm{ml}$. water added to main compartment in morning. $0.5 \mathrm{ml}$. p-hydroxybenzoic acid $(0.05 \mathrm{M})$ or $0.5 \mathrm{ml}$. water tipped in from side arms. $A$, spores adapted by overnight incubation with $p$-hydroxybenzaldehyde; $N A$, spores incubated overnight with water, therefore nonadapted; - - citrinin added at 0 hr. ; - . - -, water added at 0 hr.; $I, p$-hydroxybenzoic acid added where indicated by arrow; $\boldsymbol{W}$, water added where indicated by arrow.

breakdown (Henderson \& Farmer, 1955). Thus it can be seen from Fig. 1 that previous incubation in the presence of $p$-hydroxybenzaldehyde led to an immediate uptake of oxygen on addition of $p$-hydroxybenzoic acid. Where incubation had taken place in the absence of $p$-hydroxybenzaldehyde there 
was a period of slow oxygen uptake following the addition of $p$-hydroxybenzoic acid before the maximum rate was reached. Similar results were obtained with the other compounds. During the same period, Haplographium sp. and Penicillium sp. showed adaptation only to $p$-hydroxybenzoic acid and did not give any increase in the oxygen uptake in the presence of syringic and vanillic acids. However, the growth experiments had revealed that Penicillium sp. did decompose vanillic acid, although the syringic acid formed from syringaldehyde accumulated in the medium and was not further decomposed. Therefore it seemed probable that a longer period of incubation and adaptation might lead to oxidation of vanillic acid. In order to start growth the spores were incubated for $16 \mathrm{hr}$. in the presence of yeast extract. Vanillin was then tipped in and after a further $8 \mathrm{hr}$. of incubation vanillic acid was added. Following the addition of the acid the spores were incubated for another $16 \mathrm{hr}$. before the oxygen uptake was recorded. The increase in uptake, compared with the control, showed that vanillic acid was now being oxidized. A similar long experiment in which vanillin and vanillic acid were replaced by syringaldehyde and syringic acid confirmed that Penicillium sp. did not oxidize syringic acid, since no additional oxygen was consumed in its presence.

Inhibition of adaptive responses of spore suspensions by antibiotics

Evidence has been obtained which indicates that certain antibiotics function by inhibiting adaptive enzyme formation. Fitzgerald \& Bernheim (1948) found that streptomycin inhibited the formation of benzoic acid oxidase, an adaptive enzyme, in mycobacteria. Streptomycin, citrinin and thiolutin were therefore tested for their ability to inhibit adaptive enzyme formation with the organisms used here. The responses were found to vary. Streptomycin at $300 \mu \mathrm{g} . / \mathrm{ml}$. had no inhibitory effect, whereas Fitzgerald \& Bernheim (1948) obtained complete inhibition at $200 \mu \mathrm{g} . / \mathrm{ml}$. Citrinin at $83 \mu \mathrm{g} . / \mathrm{ml}$. decreased adaptation by Hormodendrum sp. to $p$-hydroxybenzoic, vanillic and syringic acids. The effect was shown most clearly with $p$-hydroxybenzoic acid (Fig. 2). When the acid oxidase had been formed as a result of incubation in the presence of $p$-hydroxybenzaldehyde, the addition of $p$-hydroxybenzoic acid caused an immediate increase in the rate of oxygen uptake, whether citrinin was present or not. However, when there was no period of preincubation with the precursor, citrinin decreased considerably the rate of oxygen uptake as compared with that found for the flask to which no citrinin had been added, and the typical adaptive curve was not produced. Citrinin at $83 \mu \mathrm{g} . / \mathrm{ml}$. did not affect the adaptation of Haplographium sp. and Penicillium sp. to $p$-hydroxybenzoic acid but at $357 \mu \mathrm{g} . / \mathrm{ml}$. adaptation was almost completely stopped.

The influence of citrinin in decreasing the formation of enzyme required for oxidation of vanillic acid by Hormodendrum sp. has been confirmed by a method based on Kluyver \& van Zijp's (1951) technique. Mats of the fungus were grown by inoculating with spores $100 \mathrm{ml}$. volumes of mineral salts medium (see methods), to which were added yeast extract $(0.5 \%, \mathrm{w} / \mathrm{v})$ and glucose $(1 \%, w / v)$. The cultures were grown in $250 \mathrm{ml}$. conical flasks. After 7 days of incubation at $21^{\circ}$ the medium was poured off and the mats washed three times 
with sterile distilled water. Citrinin (500 $\mu \mathrm{g}$. $/ \mathrm{ml}$.) was present in the solution of vanillin $(0 \cdot 1 \%, \mathrm{w} / \mathrm{v})$ added to the mats. After 5 days of incubation, analysis of the solution by paper chromatography (Henderson \& Farmer, 1955), revealed that there was a considerable amount of vanillic acid present in the culture containing citrinin, and in the control to which no citrinin had been added. After 10 days of incubation there was still a large amount of vanillic acid in the citrinin-containing culture but none remained in the control which indicated that citrinin was preventing decomposition of the acid.

Thiolutin was found to be non-specific for adaptive enzyme formation; it inhibited the oxidation of $p$-hydroxybenzaldehyde and $p$-hydroxybenzoic acid to the same degree.

\section{DISCUSSION}

Spore suspensions have been used previously for respiration studies in the Warburg apparatus (Mandels, 1947; Shirk \& Byrne, 1951), but these investigations were made directly after harvesting. In the present work, however, the spores were preincubated for a period of $16-17 \mathrm{hr}$., usually in the presence of yeast extract, which is known to induce rapid germination (Mandels, 1947). The use of spore suspensions as here reported is superior in several ways to the methods which use grown mycelium. One advantage is the uniformity, both quantitative and physiological, which can be obtained between vessels. When using mycelium, discrepancies arise on account of the varying water contents of the samples and the varying physiological activities within the material which consists of hyphae of different ages. A further advantage is that in studying the activity of germinating spores, the physiology of a whole organism is being considered. This is not so when working with mycelial suspensions which contain fragments of mycelium consisting of a few cells. The metabolism of the cells is disorganized in the preparation of the suspensions, as shown, for example, by Darby \& Goddard (1950) who found that the $Q_{\mathrm{o}_{2}}$ was influenced by the extent of blending, increasing maceration leading to decreasing activity.

The low rate of endogenous respiration in germinating spores as compared with the very high rates with mycelia is also an important factor. The high endogenous rates with mycelia mask much of the effect on oxygen uptake brought about by the addition of utilizable substrates.

The results presented in this paper confirm the findings previously obtained by growth experiments and analyses of culture fluids (Henderson \& Farmer, $1955)$ concerning the ability of certain fungi to metabolize $p$-hydroxybenzaldehyde, ferulic acid, syringaldehyde and vanillin. Both investigations showed that $p$-hydroxybenzaldehyde was more rapidly oxidized than were the other compounds. The presence of one or two methoxyl groups attached to the benzene ring in the other compounds may account for the slower rate at which they were attacked. Support for this view is obtained from the fact that syringaldehyde, with two methoxyl groups, was more slowly attacked than were ferulic acid and vanillin with one each.

In addition, information has been obtained on the process of oxidation of the intermediate products, $p$-hydroxybenzoic, syringic and vanillic acids. A study 
of the rate of oxygen uptake in the presence of these compounds showed that they are adaptively attacked. Since preincubation of the spores in the presence of $p$-hydroxybenzaldehyde, ferulic acid, syringaldehyde or vanillin eliminated the lag period before the maximum rate of oxygen uptake was reached after addition of the intermediates, the following conversions appear to be confirmed: $p$-hydroxybenzaldehyde $\rightarrow p$-hydroxybenzoic acid; ferulic acid and vanillin $\rightarrow$ vanillic acid; syringaldehyde $\rightarrow$ syringic acid.

I wish to thank Dr D. M. Webley for his interest and advice and Miss D. Brebner for technical assistance. I am also grateful to Professor A. Robertson for giving me a sample of citrinin.

\section{REFERENCES}

CLARK, W. M. (1928). The Determination of Hydrogen Ions, 3rd edn. London: Baillière, Tindall and Cox.

DARBy, R. T. \& Goddard, D. R. (1950). Studies on the respiration of the mycelium of the fungus Myrothecium verrucaria. Amer. J. Bot. 37, 379.

Fitzgerald, R. J. \& Bernheim, F. (1948). 'The effect of streptomycin on the formation of adaptive enzymes. J. Bact. 55, 765 .

Henderson, M. E. K. (1955). A method for studying the metabolism of fungi in the Warburg apparatus using spore suspensions. J. gen. Microbiol. 12, iii.

Henderson, M. E. K. \& FARMer, V. C. (1955). Utilization by soil fungi of $p$-hydroxybenzaldehyde, ferulic acid, syringaldehyde and vanillin. J. gen. Microbiol. 12, 37.

Kluyver, A. J. \& van ZiJP, J. C. M. (1951). The production of homogentisic acid out of phenylacetic acid by Aspergillus niger. Leeuwenhoek ned. Tijdschr. 17, 47.

Mandels, G. R. (1947). Respiration and germination of Myrothecium verrucaria spores. Amer. J. Bot. 34, 595.

ShIrK, H. G. \& ByrNe, H. E. (1951). Effect of some nitrophenols on the respiration of Myrothecium verrucaria spores. J. biol. Chem. 191, 783.

Silliker, J. H. \& Rittenberg, S. C. (1951). Studies on the aerobic oxidation of fatty acids by bacteria. II. Application of the technique of simultaneous adaptation to the study of the mechanism of fatty acid oxidation in Serratia marcescens. J. Bact. 61, 661.

Stanier, R. Y. (1947). Simultaneous adaptation: a new technique for the study of metabolic pathways. J. Bact. 54, 339.

(Received 16 December 1955) 